\title{
The Effect of Foreign Direct Investment on the Unemployment Rate in Saudi Arabia
}

\author{
Kolthoom Alkofahi ${ }^{1}$ \\ ${ }^{1}$ Prince Sultan University, Saudi Arabia \\ Correspondence: Kolthoom Alkofahi, Prince Sultan University, Saudi Arabia. E-mail: kkofahi@psu.edu.sa
}

Received: July 9, 2020

Accepted: August 24, 2020

Online Published: September 5, 2020

doi:10.5539/ijef.v12n10p1

URL: https://doi.org/10.5539/ijef.v12n10p1

\begin{abstract}
A substantial number of recent studies were devoted to investigating the effects of Foreign direct investment (FDI) on different economic variables. Although the connection between growth and investments is widely acknowledged, the connection between FDI and the unemployment rate is not easy to determine. Taking into consideration the dispute over the true effect of FDI on the host country's economic performance, the study's main purpose is to take advantage of the dispute and study the effect of foreign direct investment (FDI) on the unemployment rate (U) in the Kingdom of Saudi Arabia (KSA). Using Ordinary Least Square Model (OLS), the study takes the unemployment rate as a dependent variable, and FDI and Output as two explanatory variables over the period of 2005-2018. The study supports our assumption that the inflows of the FDI and the total output negatively and significantly affect the unemployment rate in the KSA; the inflows of the FDI creates more job opportunities and will reduce the unemployment rate in KSA. Our recommendation is that the KSA government should implement more policies to attract more inflows of "Quality FDI" to attain the maximum goals and to decrease the total unemployment rate.
\end{abstract}

Keywords: Foreign Direct Investment (FDI), gross domestic product, unemployment rate, Ordinary Least Square Regression, Saudi economy

\section{Introduction}

The government of Saudi Arabian implemented the vision 2030 that sets out a blueprint for the future of Saudi Arabia to reduce its dependency on oil and to increase private sector participation. The Vision has ambitions that aim at achieving long term goals such as increasing the number of job opportunities, especially in the private sector, securing meaningful employment for Saudi citizens, and reducing the unemployment rate for Saudi citizens. One of the channels through which this study suggests achieving these goals is through attracting more inflows of Foreign Direct Investment (FDI) as it is considered the engine that enhances economic performances for different sectors of the economy.

KSA is considered the largest destination for FDI in the Arab world as it enjoys a growing economy and it has a large-scale infrastructure investment. According to figures from a special report issued by the Saudi Arabian General Investment Authority for the Summer of 2019, foreign direct investment inflows increased by $24 \%$ in Q1 2019. In the first half of the year, new foreign investor licenses rose by $85 \%$ and economic reforms implemented by the National Competitiveness Centre hit 55\%. Major investor deals are being signed and giga-projects continue to move ahead. Investors all over the world are bringing their businesses to the Kingdom, with major new investors in the last quarter from the UK, USA, France, Egypt, China, and India among many others, with the US and China being the largest sources of foreign direct investment in the Kingdom. Having said that, KSA should focus more on attracting what is called "Quality FDI" that links foreign investors into the local host country's economy. FDI is considered a quality FDI if it contributes to the creation of decent and value-adding jobs, enhances the skill base of host economies, facilitates the transfer of technology, knowledge and know-how, boosts the competitiveness of domestic firms and enabling their access to markets, and operates in a socially and environmentally responsible manner (Moran et al., 2017).

On the other hand, one agenda that all governments try to achieve is to decrease the unemployment rate through the creation of more job opportunities either in public or private sectors. In this regard, many authors emphasized the critical role that FDI plays in increasing the economic growth of developing countries and in encouraging the creation of new jobs and enhancing technology transfer that boosts overall economic growth (Wang \& 
Blomström, 1992). Dritsaki and Stiakakis (2014) also emphasized the positive role of FDIs; more FDIs increase the provision of funds for domestic investments, encourage the creation of new jobs, reinforce the technology transfer, and increase in total economic growth.

A substantial number of recent studies were devoted to investigating the effects of Foreign direct investment (FDI) on different economic variables. Although the connection between growth and investments is widely acknowledged, the connection between FDI and unemployment is not easy to tackle. Some economists argue that FDI inflows have a positive impact on the labor market only for the skilled workforce (Pandya, 2010), others argue that the impact of foreign direct investment on total employment and productivity in developing countries is mostly positive, but in advanced countries foreign direct investment effects are combined (Hale \& $\mathrm{Xu}, 2016)$.

As for the KSA economy, this kind of relationship is ambiguous. Although the inflows of FDI has created employment opportunities and increased gross domestic product (GDP) in KSA (Ramaday et al., 2007), Albassam, B._(2015) found no relationship between FDI and economic growth in Saudi Arabia. Finally, Said Jaouadi (2014) stated that the inflows of FDI increased the joblessness in the KSA economy.

Taking into consideration all the debate and the dispute about the true relationship between FDI and unemployment rate in Saudi Arabia, this article employs a different econometrics approach and more revised and recent data to clear the ambiguity over the true nature of the relationship and hopefully will support our assumption that FDI negatively and significantly affect the level of unemployment rate in KSA.

The rest of this paper is structured as follows. Section 2 presents an overview of some related literature that studied the relationship between FDI and U. Section 3 outlines the data and the methodology that is used to analyze the data. Section 4 reports and analyzes the empirical findings for total U in KSA followed by a case study Saudi U to help implement policy. Finally, Section 5 final conclusions and future suggestions.

\section{Literature Review}

The role of FDI in enhancing economic performance has been widely discussed in the literature. However, as explained above, few studies focused on the effect of FDI on U, and if so, the results are different among the studies. The first part of this section aims at reviewing some articles that describe, in general, the quantitative assessment effect of FDI on the level and the rate of employment and unemployment, while the second part reviews more literature that focused on analyzing the KSA economy in the related filed.

A study by Nayyra, Fu, and Muhammad (2014) supports our assumption that FDI produces a negative effect on U. The study tested the impact of FDI, among other explanatory variables, on Unemployment in Pakistan in the period of 1995-2011. Using multiple regression analysis, their finding supported the theoretical background of the significant roles that FDI creates to the hosting county; according to the study, a 1\% increase in FDI will reduce unemployment by $2.75 \%$. hence, the authors proposed a different way to attract capital inflows and hence decrease unemployment in Pakistan. A similar result was found by Stamatiou and Dritsakis (2014). The study investigated the relationship between the unemployment rate, foreign direct investment, and economic growth in Greece during the period 1970-2012. applying different econometric models on annual data, the results emphasized on the long-run relationship among the variables, and that FDI increases as unemployment decreases in both terms; the long-run relationship showed that a $1 \%$ decrease in unemployment will increase FDI by $0.27 \%$, and the short-run relationship showed that, a $1 \%$ decrease in the unemployment rate will increase FDI by $0.36 \%$. After all, analysis showed that increased FDI in both terms increases growth rate and decreases unemployment, which triggered the authors to encourage the Greek government to implement policies to attract foreign direct investments and foreign capital since more FDI will boost economic development and reduces unemployment. However, a study by Aktar and Ozturk (2009) didn't support our assumption. The paper uses quarterly data from 2000 to 2007 of FDI, unemployment rate, export, and GDP, and employed VAR techniques of variance decomposition and impulse response function. The results showed that FDI has no contribution to decreasing the unemployment rate in Turkey. However, the results also showed that export attracted more inflows of FDI and that more policies should be implemented to increase exports and increase the skills of the laborers in Turkey.

This ambiguity of the nature of the relationship between FDI and U also arises when using KSA data. For example, Albassam (2015) studied the impact of foreign direct investment on economic growth and employment in Saudi Arabia during the period of 1999 to 2012. Using the VAR model, the study found no relationship between FDI and economic growth in Saudi Arabia and also found that FDI inflows contribute positively to the employment rate, but one should keep in mind that half of the Saudi workforce is employed by the public sector. On the other hand, Said Jaouadi (2014) study didn't support our assumption. The study found that FDI increases the joblessness in the KSA Economy. His study focused on clarifying the long run and short-run relationship 
between foreign investment and unemployment in KSA during the period 1991-2012. Using annual data for foreign direct investment and unemployment of youth, the paper investigated the possibility of causality and the long run and short-run relationship between the two variables. In contrast with the theoretical background that the foreign investment has a positive impact on the economic growth spillover in host-country, the findings revealed that the inflows of FDI increased the joblessness in the KSA economy; as FDI increased by 1\%, the unemployment in KSA increased by $0.09 \%$. The paper also shed some light on the high economic inefficiency of the labor market in KSA that was caused by the rigidity of the wages of Saudi workers and the labor importing policies. To enhance labor market efficiency, the Saudi government increased its intervention, by implementing some restrictions on labor. The Saudi government decided to limit the labor importing (quotas) and to restrict the ability for foreigners to change occupation. The impact of such policies on enhancing the efficiency of the labor market, will be the real highway for FDI to reduce unemployment in KSA.

In summary, after reviewing the literatures, one can point out that the studies have insofar been inconclusive on whether the FDI helps the economies in reducing the unemployment rate especially for that of KSA. Hence, this study will re-assess this relationship for KSA economy using a simple traditional method that is considered as the yardstick for econometric models; OLS regression.

\section{Data and Methodology}

\subsection{Data}

The paper study the factors that could affect the unemployment rate in Saudi Arabia other than foreign direct investment. Unfortunately, due to the unavailability of the data or due to the short time series of the relevant FDI data set, the sample of the study covers the period between 2005 and 2018. The study employs the unemployment rate as the dependent variable (U), foreign direct investment as a percentage of GDP (FDI) and the gross domestic product measured in constant international prices 2011(GDP) as two explanatory variables.The study also adds the inflation rate (Infl) measured by the consumer price index as a control variable. The data were collected from two different sources; Unemployment rate data were collected from the SAMA annual book, and the world bank table to collect the time series data for the FDI, GDP, and infl.

\subsection{Methodology}

The main purpose of this study is to shed some light on the role of foreign direct investment in decreasing the unemployment rate in Saudi Arabia using time series data set over the period of 2004-2018. This study is not only interested in finding the nature of such a relationship, it is also interested in measuring the absolute change in the unemployment rate for a percent change in FDI. Hence, as a first step in measuring the empirical evidence of the FDI effect on unemployment rate, this study employs the Ordinary Least Square Model (OLS) using the semi-log functional transformation form.

The semi-log form is a variant of the double-log equation in which some but not all the variables (dependent and independent) are expressed in terms of their natural logs. The model of the study is summarized in equation (1).

$$
U_{t}=\beta_{0}+\beta_{1} \ln F D I_{t}+\beta_{2} \ln G D P_{t}+\beta_{3} \operatorname{Infl}_{t}+u_{t}
$$

Where $\beta_{0}$ is a constant term, $\beta_{i}$ 's are the slope parameters to be estimated $(i=1,2,3)$, and $u_{t}$ is a disturbance term.

To proceed with the analysis, we should make some assumptions that will be explained in the following sections. If the assumptions hold, then this model is considered adequate and satisfies the needs of the purpose of this paper.

For testing the parameters, the model assumes the null and the alternative hypothesis regarding the slope parameters as follows:

$H_{0}$ : the estimated parameter $\beta_{i}$ is equal to zero.

$H_{1}$ : the estimated parameter $\beta_{i}$ is not equal to zero.

In fact, this study predicts that all the slope parameters are negative; $\beta_{1}$ reflects the impact of FDI on U, so more net inflows of FDI create more job opportunities and could contribute to a reduction in $\mathrm{U}$, for this reason, $\beta_{1}$ is expected to be negative. As the country expands its gross domestic product, it needs to hire more workers, and hence, it is considered a major factor to reduce the unemployment rate in KSA. As a result, $\beta_{2}$ is expected to be negative. Finally, $\beta_{3}$ is expected to be negative since it reflects the relationship between inflation rate and the unemployment rate which is widely known by the Philips curve; the unemployment rate and the inflation rate have stable and inverse relationship. 


\subsubsection{An Overview of the OLS Model}

The Ordinary Least Square Model (OLS) is attributed to Carl Friedrich Gauss, a German mathematician, and has some very attractive statistical properties that have made it one of the most powerful and popular methods of regression analysis. The general form of the multiple regression model that we will apply in this study is as follows:

$$
Y_{t}=\beta_{0}+\beta_{1} X_{1 t}+\beta_{2} X_{2 t}+\beta_{3} X_{3 t}+u_{t}
$$

$\beta_{i}$ 's are the OLS parameters to be estimated and are expressed solely of the observable quantities of Y and X's. for more explanation, $\beta_{0}$ is the intercept term. As usual, it gives the mean or average effect on $Y_{t}$ if all the variables excluded from the model, although its mechanical interpretation is the average value of $Y_{t}$ when $X_{1 t}, X_{2 t}$, and $X_{3 t}$ are set equal to zero. $\beta_{1}$ measures the expected change in the mean value of $Y_{t}, \mathrm{E}(\mathrm{Y})$, per unit change in $X_{1 t}$, holding the value of $X_{2 t}$ and $X_{3 t}$ constant. Put differently, it gives the "direct" or the "net" effect of a unit change in $X_{1 t}$ on the mean value of $Y_{t}$, net of any effect that $X_{1 t}$ may have on mean $Y$. Likewise, you can interpret the $\beta_{2}$ and $\beta_{3}$ in the same fashion. Finally, $u_{t}$ is a stochastic disturbance term.

The expected value of the $Y_{t}$ using the OLS estimates takes the general form:

$$
Y_{t}=\hat{\beta}_{0}+\hat{\beta}_{1} X_{1}+\hat{\beta}_{2} X_{2 t}+\hat{\beta}_{3} X_{3 t}+\hat{u}_{t}
$$

Where the estimated values of $Y_{t}$ is $\hat{Y}_{t}$ and can be written as follows:

$$
\hat{Y}_{t}=\hat{\beta}_{0}+\hat{\beta}_{1} X_{1}+\hat{\beta}_{2} X_{2 t}+\hat{\beta}_{3} X_{3 t}
$$

In short, the OLS procedure consists of choosing the values of the unknown $\beta_{i}$ 's so that the residual sum of square (RSS) is as small as possible. Symbolically,

Writing the equation in another form:

$$
\min \sum \hat{u}_{t}^{2}=\min \sum\left(Y_{t}-\hat{Y}_{t}\right)^{2}
$$

$$
\min \sum \hat{u}_{t}^{2}=\min \sum\left(Y_{t}-\hat{\beta}_{0}-\hat{\beta}_{1} X_{1}-\hat{\beta}_{2} X_{2 t}-\hat{\beta}_{3} X_{3 t}\right)^{2}
$$

The following should highlight the classical linear assumptions that must be held for the OLS to be a valid estimate:

1) the regression is linear in parameters (not necessarily in variables).

2) The values of $X$ and $Y$ are independent of the error term.

3) The disturbance term must have zero mean.

4) Homoscedasticity or Constant variance of the error term.

5) No autocorrelation, or serial correlation between the disturbances.

6) The number of observations $n$ must be greater the number of parameters to be estimated. Which is 4 in this study.

7) There must be variation in the $X$ variables.

If these assumptions were satisfied, then this OLS regression is said to BLUE, the best linear unbiased estimators for the model.

\section{Empirical Results}

This section applies the methodology on two different set of unemployment rates; the first section dedicates to the total unemployment rate in KSA, and the other section uses only the unemployment rate for Saudi participants.

\subsection{Case 1: Taking the Total Unemployment Rate in KSA as a Dependent Variable}

This study assumes that hosting more FDI creates more job opportunities and reduces the unemployment rate. Hence, it tries to empirically investigates the slope parameters of equation (1) using OLS regression. Table 1 below presents the empirical results of the regression of equation (1) over the period 2005-2018.

The regression equation reported in table 1 can be written as:

$$
\widehat{U}_{t}=93.7745-0.4029 \operatorname{lnFDI}_{t}-3.1362 \ln G D P_{t}-0.0389 \text { infl }_{t}
$$

The results produced in the table significantly support our assumption; FDI significantly reduces the U in KSA. The table also shows that more GDP and higher inflation rate reduce $\mathrm{U}$ in KSA. $\beta_{1}$ represent the partial effect of FDI on U, as expected, holding the GDP and INFL constant, as FDI increases by $1 \%$, the Unemployment rate 
decreases by $0.4029 \%$ and is significant at $1 \%$ significance level. $\beta_{1}$ represent the partial effect of GDP on U, holding the FDI and the INFL constant. The results also show that $\beta_{2}$ is negative and statistically significant at a $1 \%$ significance level, it exerts that there is a negative relationship between gross domestic product in KSA and the unemployment rate; as output increases by $1 \%$, the unemployment rate decreases by $3.1362 \%$, holding the FDI and INFL constant. $\beta_{3}$ is negative; holding the FDI and GDP constant, as the inflation rate increases by $1 \%$ the unemployment rate decreases by $0.0387 \%$ but it is not significant. Finally, the conditional mean of the unemployment rate when FDI, GDP and INFL are all set to zero is equal to $\beta_{0}=93.7745$ and is significant at $1 \%$ significance level. The fitness of the regression can be predicted form $R^{2}$, it reflects that $66.52 \%$ of the total variability in the unemployment rate is explained by the variation in the FDI, GDP, and INFL. The table also discards the possibility of the existence of autocorrelation between the explanatory variables, this can be proved by the Durbin-Watson statistics that is around 2. And finally, the overall test of the regression is statistically significant at $1 \%$ significance level; the p-value of the F-statistic is equal to 0.0097. After all, this table supports our assumption about the true importance of FDI in lowering the unemployment rate in Saudi Arabia.

Table 1. OLS regression, dependent variable is the unemployment rate $U_{t}$

\begin{tabular}{lcccc}
\hline \multicolumn{1}{c}{ Variable } & Coefficient & Std. Error & t-statistic & P-value \\
\hline Constant & 93.7745 & 21.3001 & 4.4025 & $0.001^{* * *}$ \\
ln FDI $I_{t}$ & -0.4029 & 0.1035 & -3.8942 & $0.003^{* * *}$ \\
${\text { ln } G D P_{t}}_{\text {infl }}$ & -3.1362 & 0.7592 & -4.1311 & $0.002^{* * *}$ \\
$R^{2}$ & -0.0387 & 0.0284 & -1.3660 & 0.201 \\
F-statistic & 0.6652 & & & \\
Prop(f-statistic) & 6.624 & & & \\
Durbin-Watson stat & 0.0097 & & & \\
\hline
\end{tabular}

Note. Data labeled with ***, **, * are significant at $1 \%, 5 \%$, and $10 \%$ respectively.

One might ask if the assumption of OLS regression hold for this study. We can go with further tests to prove that this model is adequate and satisfies all the classical linear regression assumptions presented above. note that, assumption 1 is satisfied by the model (refer to table 1). However, we need to conduct some diagnostic tests for the residual to show that assumption 3 (the normality test) and 4 (heteroskedasticity test) hold; the disturbance term must have zero mean and Homoscedasticity or Constant variance of the error term. table 2 and 3 below summarizes the results:

Table 2. Normality test for the disturbance term

\begin{tabular}{ll}
\hline Null Hypothesis: U is normally distributed & \\
Alternative Hypothesis: U is not normally distributed & \\
\hline Mean & -9.74 e- 15 \\
St. dev & 0.173 \\
Jarqu- Bera & 0.3476 \\
p-value & 0.8405 \\
\hline
\end{tabular}

As can be seen from table 2, according to Jarqu-Bera test, the null hypothesis that the error term is normally distributed with mean zero is not rejected, which means that assumption 3 is satisfied. Moreover, table 3 reported the Bresch-Godfrey test to check if the disturbance terms are Heteroskedastic. The test reported the p-value of the F-statistic is equal to 0.4079 ; it fails to reject, at 5\% significance level, that the variances are homoscedastic. In summary, table 3 and table 4 summarizes that the error terms are distributed normally with mean zero and equal variances.

Table 3. Heteroskedasticity test: Breusch-Pagan-Godfrey

\begin{tabular}{lccc}
\hline Null Hypothesis: Variances are Homoscedastic & & \\
\multicolumn{2}{l}{ Alternative Hypothesis: Variances are Heteroskedastic } & & 0.4079 \\
\hline F-statistic & 1.062420 & Prob. F (3,10) & 0.3362 \\
Obs*R-squared & 3.383692 & Prob.Chi-Square (3) & 0.7680 \\
Scaled explained SS & 1.137563 & Prob. Chi-Square (3) \\
\hline
\end{tabular}


Finally, to check if assumptions 2 and 5 are being satisfied, we conduct the Breusch-Godfrey serial correlation LM test, the results are shown in table 4 below. The table shows that the hypothesis of no autocorrelation is not rejected, at 5\% significance level; the assumptions are satisfied.

Table 4. Breusch-Godfrey serial correlation LM test

\begin{tabular}{llll}
\hline $\begin{array}{l}\text { Null Hypothesis: No serial correlation } \\
\text { Alternative Hypothesis: serial correlation }\end{array}$ & & \\
\hline F-statistic & 0.096830 & Prob. F $(1,9)$ & 0.7628 \\
Obs*R-squared & 0.149021 & Prob. Chi-Square (1) & 0.6995 \\
\hline
\end{tabular}

After all, we can see that the result of the regression and the diagnostic tests for the residual show that the classical linear assumptions for the OLS regression are all satisfied, hence using the OLS regression is adequate and the results produced by the model can be reliable. We can then rely on the results produced by table 1 and emphasize on the importance of FDI in reducing the unemployment rate in KSA, this give the policy makers a guide to target a new channel through which the unemployment rate could deflate in KSA. However, one could ask if the FDI helps the Vision 2030 to achieve its goal in regards of the unemployment rate for the Saudi participants in the labor force; is it possible to achieve a lower unemployment rate for Saudi citizen knowing that they most likely prefer working at the public facilities? The next subsection takes this question into consideration to see whether to even target more FDI in KSA.

\subsection{The Empirical Results: A Glance Over the Saudi Vision and the Unemployment Rate in KSA}

According to a report by Harvard Kennedy School (2019), the Saudi vision aims at reducing the unemployment rate for Saudi citizens to 9 percent (currently at 12.8 percent) by 2020. In order to achieve this goal, policymakers should consider not only the total unemployment rate, but also the unemployment rate for Saudi citizen in order to effectively reduce the total unemployment rate in KSA. Table 5 reports the unemploment rate in KSA for saudi and non-saudi participants.

By taking a closer look at the labor force in KSA, one can see that the KSA total unemployment rates consists of Saudi and Non-Saudi participants. Accordingly, the unemployment rate in KSA is calculated by taking the average of the Saudi (U-Saudi) and Non-Saudi (U-Non-Saudi) unemployment rates. This method clearly deflates the true Unemployment rate in KSA and consequently affects the decisions that policymakers take. One should point out that the correct method to use is to take a weighted average of the unemplyment rate and not just the average. The data for the unemployment rates in KSA were extracted from SAMA annual reports during the period of 2005-2018 and are represented in Table 5. As can be seen from the table, the unemployment rates for Saudi participants is extremely high during the period; it reached a minimum of $10 \%$ in 2008 and a maximum of $12.8 \%$ in 2017. One of the reasons for high unemployment rates is that most Saudis job seekers gravitate towards public-sector employment, as it provides higher wages, more comprehensive benefits, and greater job security than the private sector does.

Table 5. The Unemployment rate in KSA, 2005-2009

\begin{tabular}{lccc}
\hline Year & \multicolumn{3}{c}{ Unemployment rate in KSA } \\
\cline { 2 - 4 } & Saudi & Non-Saudi & Average \\
\hline 2004 & $11 \%$ & $0.8 \%$ & $5.82 \%$ \\
2005 & 11.52 & 0.8 & 6.10 \\
2006 & 12 & 0.8 & 6.30 \\
2007 & 11.2 & 0.6 & 5.80 \\
2008 & 10 & 0.5 & 5.20 \\
2009 & 10.5 & 0.3 & 5.40 \\
2010 & 11.2 & 0.4 & 5.50 \\
2011 & 12.4 & 0.39 & 5.80 \\
2012 & 12.1 & 0.08 & 5.50 \\
2013 & 11.7 & 0.2 & 5.60 \\
2014 & 11.7 & 0.3 & 5.70 \\
2015 & 11.5 & 0.5 & 5.60 \\
2016 & 11.6 & 0.6 & 5.60 \\
2017 & 12.8 & 0.9 & 6.00 \\
2018 & 12.7 & 1 & 6.00 \\
\hline
\end{tabular}

Source: SAMA annual Report. 
For the purpose of this paper, a time series trend for the FDI, U, U-Saudi, U-Non-Saudi are depicted in Figure 1. By looking at the time series for FDI and the total Unemployment rate, we can see that the trends confirm the results in Table I, moreover, this kind of relationship is more obvious when it comes to comparing the U-Saudi and FDI trends; there is a strong negative correlation: as FDI increases, U-Saudi decreases. However, one might notice that this is not true for the period of 2008-2009 which is true due to the global economic crisis that occurred in 2008.

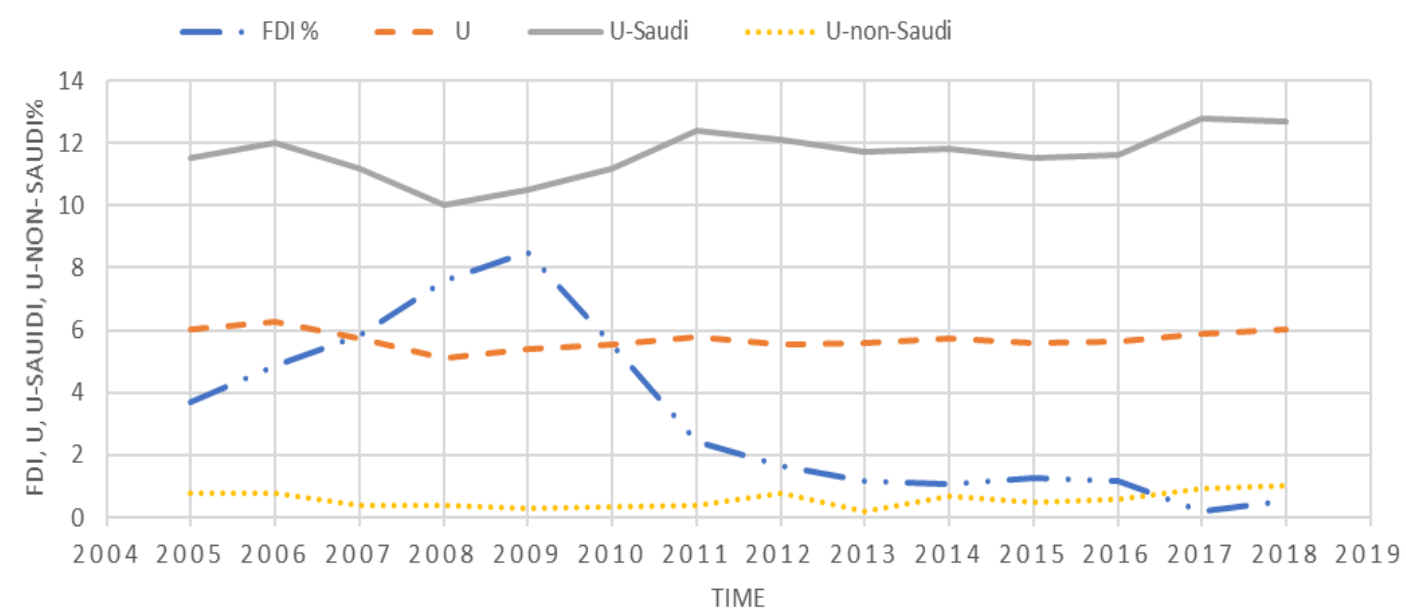

Figure 1. FDI, Unemployment rates in KSA (Source: developed by the author)

In order to see whether FDI significantly decreases the U-Saudi, an OLS regression using equation (8) is conducted. Taking the U-Saudi as a dependent variable, the results of the estimation are represented in Table 6.

$$
\text { USaudi }_{t}=\beta_{0}+\beta_{1} \operatorname{lnFDI}_{t}+\beta_{2} \ln G D P_{t}+\beta_{3} \operatorname{Infl}_{t}+u_{t}
$$

Table 6. OLS regression, dependent variable is the Saudi unemployment rate $\boldsymbol{S} \boldsymbol{U}_{\boldsymbol{t}}$

\begin{tabular}{lcccc}
\hline \multicolumn{1}{c}{ Variable } & Coefficient & Std. Error & t-statistic & P-value \\
\hline Constant & 91.3278 & 54.4894 & 1.6761 & 0.124 \\
$\ln F D I_{t}$ & -0.85779 & 0.2647 & -3.2408 & $0.009^{* * *}$ \\
$\ln G D P_{t}$ & -2.8261 & 1.9421 & -1.4552 & 0.1763 \\
$\operatorname{infl} l_{t}$ & -0.0266 & 0.0725 & -0.3674 & 0.7209 \\
$R^{2}$ & 0.6746 & & & \\
$F$-statistic & 6.911 & & & \\
Prop(f-statistic) & 0.0084 & & & \\
Durbin-Watson stat & 1.5604 & & & \\
\hline
\end{tabular}

Based on Table 6, the regression equation can be written as:

$$
\widehat{U S A u d i}_{t}=91.3278-0.85779 \operatorname{lnFDI}_{t}-2.8261 \ln G D P_{t}-0.0266 \operatorname{Infl}_{t}
$$

Aligned to the results in Table 1, the estimation output support our assumption; the inflow of FDI significantly decreases the U-Saudi; as FDI increases by $1 \%$, the U-Saudi will decrease by $0.8578 \%$ and is significant at a $1 \%$ significance level. The results also confirms the negative effect of GDP and INFL on the U-Saudi, however, they are insignificant. $R^{2}$ reflects the fitness of the regression; $66.52 \%$ of the total variability in the unemployment rate is explained by the variation in the FDI, GDP, and INFL, which leave almost $33.5 \%$ of the variability in U-Saudi to other explanatory variables. The overall regression is not rejected as can be seen from the propability of f-statistic (0.0084).

To test if this model is adequate, we should do some diagonestic tests for the disturbance term in a similar fashin as we did for table 1 . As expected, the results of the normality test that is reported in table 7 fail to reject that the error term is distributed normaly with zero mean. 
Table 7. Normality test for the disturbance term, dependent variable $S U_{t}$

\begin{tabular}{ll}
\hline Null Hypothesis: U is normally distributed & \\
Alternative Hypothesis: U is not normally distributed & \\
\hline Mean & $-2.02 \mathrm{e}-14$ \\
St. dev & 0.4428 \\
Jarqu- Bera & 0.2125 \\
p-value & 0.8992 \\
\hline
\end{tabular}

Table 8 reported the Bresch-Godfrey test for Heteroskedasticity. The test fails to reject, at $5 \%$ significance level, that the variances are homoscedastic. In summary, table 3 and table 4 summarizes that the error terms are distributed normally with mean zero and equal variances.

Table 8. Heteroskedasticity test: Breusch-Pagan-Godfrey

\begin{tabular}{lccc}
\hline $\begin{array}{l}\text { Null Hypothesis: Variances are Homoscedastic } \\
\text { Alternative Hypothesis: Variances are Heteroskedastic }\end{array}$ & \\
\hline F-statistic & 0.292496 & Prob. F(3,10) & 0.8300 \\
Obs*R-squared & 1.129382 & Prob. Chi-Square(3) & 0.7700 \\
Scaled explained SS & 0.494762 & Prob. Chi-Square(3) & 0.9200 \\
\hline
\end{tabular}

Although the estimated output in table 6 and the diagonestic test for the disturbance terms are being satisfied, the assumption for no autocorrelation among the disturbance term is alarming us to deeply check for the presence of such correlation. The low value of the Durbin-Watson statistic reported above is indicative of the presence of serial correlation in the residuals of the estimated equation. If uncorrected, serial correlation in the residuals will lead to incorrect estimates of the standard errors, and invalid statistical inference for the coefficients of the equation (Gujarati \& Porter, 2008). To correct for the autocorrelation, it is familier to manipulate the data through taking the first difference or including the first lag of the time resries. Before choosing which data manipulation we need to use, it would be necessary to refer to the Durbin-Watson statistical table, and do some diagonestic test for the disturbance term in a similar fashin as we did before.

Using the famous Durbin-Watson statistic table, one could find that, based on 3 explanatory variables and 14 observations, the reported Durbin-Watson statistic falls in the region of no decision of autocorrelation, that is $d_{l}=0.767<1.5604<d_{u}=1.779$. the region of no decision of autocorrelation does not mean there is no autocorrelation. Hence, as a next step, it is necessary to perform a more general BreuschGodfrey test for serial correlation (LM test) in the residuals. The test result is reported in table 9 below.

Table 9. Breusch-Godfrey serial correlation LM test (the dependent variable $S U_{t}$ )

\begin{tabular}{lccc}
\hline $\begin{array}{l}\text { Null Hypothesis: No serial correlation } \\
\text { Alternative Hypothesis: serial correlation }\end{array}$ & & & \\
\hline F-statistic & 0.3669 & Prob. F(1,9) & 0.5597 \\
Obs*R-squared & 0.5483 & Prob. Chi-Square(1) & 0.4590 \\
\hline
\end{tabular}

The top part of the output presents the test statistics and associated probability values. The test regression used to carry out the test is reported below the statistics. The statistic labeled "Obs*R-squared" is the LM test statistic for the null hypothesis of no serial correlation. The (effectively) zero probability value strongly indicates the presence of serial correlation in the residuals. The test results in table 9 fails to reject that there is no serial correlation among the disturbance term, which suggest that no data manipulation is necessary and that the results reported in the model are adequate for this study. It means whether we employ the total unemployment rate for KSA or if it is only carried for Saudi participants, the FDI significantly reduces the unemployment rate in KSA.

\section{Conclusion}

One of all countries' main target is to create more job opportunities, not only provided by public sectors but also by private sector. This paper consideres that atracting more inflows of FDI is one of the multi channels through which this target can be achieved. FDI is believed to bring more job opportunities which could reduce the unemployment rate in the hosting countries. Although this statement was supported by different research papers, 
others were against it. This article takes into consideration the dispute over the true effect of FDI on the KSA's unemployment rate to support or refute the statement. Using the unemployment rate as a dependent variable, FDI, GDP, and infl as independent variables, this paper empirically studies and assess the nature and the possible influence that FDI exerts on the total unemployment rate in KS and the unemployment rate for saudi participants using the OLS regression over the period of 2005 and 2018. This period shows that the net inflows of FDI were positive and hence allow us to use the linear -log transformation model. The empirical results of the study revealed that when taking the total unemployment rate in KSA as a dependent variable, as FDI and GDP increase by $1 \%$ the unemployment rate decreases by $0.4029 \%$ and $3.1362 \%$ and are significant at $1 \%$ significance level, but the same is not true for the Infl. however, the fitness of the regression is $66.52 \%$ and the overall test was not rejected at $1 \%$ ignificance level. The estimated results aslo proved that the OLS regression is proved to be adequate and that all classical linear assumptions hold. After applyning some diagonestic tests for the disturbance term, the results failed to reject that the model in inadequate.

The 2030 Saudi vision is hoping to reduce the unemployment rate to $9 \%$, according to the study, FDI also helps at reducing not only the total unemployment rate in KSA, but also for the saudi participants. According to the results, when taking the U-Sudi as a dependent variable, as FDI and GDP increase by $1 \%$ the unemployment rate decreases by $-0.85779 \%$ and is significant at $1 \%$ significance level. Eventhough the study shows that GDP and Inlf reduces the Saudi-U, the estimates were insignificant. The overall test was not rejected and the fitness of the regression is $67.46 \%$.

One might argue that both estimates presented in table 1 and table 6 are overestimating the true values of the parameters, however, since the unemployment rate depends on other factors that are not presented by the model, the answer is that the main purpose of this paper is to prove the general effect of FDI on the total unemployment rate and saudi unemployment rate in KSA. Another study could be conducted to incorporate more factors that could affect the unemployment rate other than the facors presented by the model such as labor market-specific factors.

In summary, this study proved that the inflows of FDI reduces the unemployment rate in KSA. The finding of this study supports the statement that FDI exert direct and indirect effect on the local economy; inflows of FDI brings better technology and know-how business, it also creates a spillover to the local firms and labor. For these reasons, in addition to our findings, our recommendation is that since KSA is considered as the largest destination of FDI in MENA region, the KSA government should encourage more first-time FDI and attract more "Quality FDI". The "Quality FDI" links foreign investors into the local host country's economy and contributes to the creation of decent and value-adding jobs. The KSA government should also conduct some policy reforms to reduce restrictions and issue licenses to foreign firm, and a final recommendation is that the KSA government should provide open, transparent, and dependable conditions for all kinds of firms, whether foreign or domestic, including the ease of doing business, access to imports, relatively flexible labor markets and protection of intellectual property rights. By doing so, we can expect that KSA will be one of the top FDI destinations not only in MENA region, but also in the world. This will results in having remarkably high economic growth, increases the income per capita, and the standard of living to extremely high levels.

\section{References}

Adam, P. B., \& Mirosława, Ż. (2011). Foreign Direct Investment and Unemployment: VAR Analysis for Poland in the Years 1995-2009. European Research Studies, 14(1). https://doi.org/10.35808/ersj/306

Aktar, I., \& Ozturk, L. (2009). Can Unemployment be Cured by Economic Growth and Foreign Direct Investment in TURKEY? International Research Journal of Finance and Economics, 27, 203-211.

Albassam, B. (2015). Does Saudi Arabia's economy benefit from foreign investments? Benchmarking: An International Journal, 22(7), 1214-1228. https://doi.org/10.1108/BIJ-05-2014-0039

Alkhathlan, K. (2011). Foreign direct investment and expert growth in Saudi Arabia: A cointegration analysis. China-USA Business Review, 10(2), 137-149.

Alrabba, M. I. (2017). The Determinants of Unemployment Rate in Jordan: A Multivariate Approach. International Journal of Economics and Finance, 9(11). https://doi.org/10.5539/ijef.v9n11p109

Elimam, H. (2017). Determinants of Foreign Direct Investment in Saudi Arabia: A Review. International Journal of Economics and Finance, 9(7). https://doi.org/10.5539/ijef.v9n7p222

Harvard Kennedy School, E. F. (2019). The Labor Market in Saudi Arabia: Background, Areas of Progress, and Insights for the Future. Retrieved in February 2020 from https://epod.cid.harvard.edu/sites/default/files/2019-08/EPD_Report_Digital.pdf 
Jaouadi, S. (2014). Could foreign direct investment increase unemployment: Case of KSA. TIJ's Research Journal of Economics \& Business Studies - RJEBS, 3(9), 51-56.

Meteb, A. M. (2017). Unemployment and Economic Growth in Saudi Arabia 2000-2015. International Journal of Economics and Finance, 9(9), 83-93. https://doi.org/10.5539/ijef.v9n9p83

Moran, T. H., Görg, H., Seric, A., \& Krieger-Boden, C. (2017). How to Attract Quality FDI? (Vol. 2). Leibniz Information Centre for Economics, KCG Policy Paper,.

Nayyra, Z., Fu, Q., \& Muhammad, S. S. (n.d.). Foreign Direct Investment and Unemployment Reduction In Pakistan. Internatonal Journal of Economic Research.

Nikolaos, D., \& Pavlos, S. (2018). Causal Nexus between FDI, Exports,Unemployment and Economic Growth for the Old European Union Members. Evidence from PanelData. International Journal of Economic Sciences, II, 35-56.

Pandya, S. (2010). Labor Maarkets and Demand for Foreign Direct Investment. International Organization, 64(3), 389-409. https://doi.org/10.1017/S0020818310000160

Saudi Arabia Governemnt Investment Agency, S. (Summer 2019). Investment Highlights, A special report by SAGIA- Summer 2019. Retrieved in March 2020, from https://investsaudi.sa/media/1658/investment-highlights-summer-2019-english-final.pdf

Saudi Arabia Monetary Authority, S. (2018). Annual Statistics 2018. Retrieved on April 1, 2020, from http://www.sama.gov.sa/en-US/EconomicReports/Pages/YearlyStatistics.aspx

Saudi Arabia Vision 2030, K. (2016). Saudi Vision 2030. Retrieved in April 2020, from https://vision2030.gov.sa/en

Stamatiou, P., \&Dritsakis, N. (2014). The Impact of Foreign Direct Investment on the Unemployment Rate and Economic Growth in Greece: A Time Series Analysis. Proceedings of the International Work-Conference on Time Series Analysis (ITISE) (Vol. 1, pp. 97-108). Granada-Spain.

World Bank, G. (2019a). Foreign direct investment, net inflows (\% of GDP). Retrieved in April 2020 from https://data.worldbank.org/indicator/BX.KLT.DINV.WD.GD.ZS

World Bank, G. (2019b). GDP, PPP (current international \$). Retrieved on April 1, 2020 from https://data.worldbank.org/indicator/NY.GDP.MKTP.PP.CD

\section{Copyrights}

Copyright for this article is retained by the author(s), with first publication rights granted to the journal.

This is an open-access article distributed under the terms and conditions of the Creative Commons Attribution license (http://creativecommons.org/licenses/by/4.0/). 